\title{
Does the theory of planned behavior elements mediate the relationship between perceived constraints and intention to participate in physical activities? A study among older individuals
}

\author{
Konstantinos Alexandris • Vasilis Barkoukis • \\ Charalampos Tsormpatzoudis
}

Received: 20 July 2006 / Accepted: 22 January 2007 / Published online: 20 February 2007

(C) EGREPA 2007

\begin{abstract}
This study aimed to investigate the degree to which the elements of the theory of planned behavior mediate the relationship between constraints and intention to continuing participation in physical activities. The sample of the study consisted of $119(N=119)$ older individuals who participated in organized physical activity programs. The results indicated that attitudes and perceived behavioral control were negatively correlated with constraints, whereas the subjective norm variable had no relationship with them. In terms of the mediation role of the elements of the theory of planned behavior, the results indicated that both attitudes and perceived behavioral control partially mediated the relationship between constraints and intention, with the perceived behavioral control variable being the strongest mediator. These findings suggest that the theory of planned behavior elements mediate the constraints-intention relationship and determine, in a large degree, the older individuals' intention to continuing taking part in physical activities.
\end{abstract}

Keywords Constraints · Theory of planned behavior . Physical activity participation

\section{Introduction}

A variety of theoretical models have been proposed in the literature for the study of physical activity and its

\footnotetext{
K. Alexandris $(\bowtie) \cdot$ V. Barkoukis $\cdot$ C. Tsormpatzoudis

Physical Education and Sport Science,

Aristotle University of Thessaloniki,

3-5 Perevou Street, Ano Toumba,

Thessaloniki 54352, Greece

e-mail: kalexand@phed.auth.gr
}

antecedents. Prominent among them are the attitudinal models, such as the theory of reasoned action and planned behavior [1-3], and the constraint models, such as the hierarchical model of leisure constraints [19] and the extended one with the inclusion of the negotiation proposition [31]. Whereas the theory of planned behavior has been widely applied both in the leisure and exercise literature (e.g., $[4,25]$ ), the constraint model has been mainly used in the leisure literature (Jackson and Scott 1999).

Studies in exercise settings investigated mainly perceived barriers to exercise without considering the hierarchical model of leisure constraints [14]. As Jackson [29] argued, the terms "barriers" and "constraints" should not be considered as synonymous. In the social-psychology literature, barriers have been categorized in two types: The first type includes factors "that slow or stop health behaviors, such as depression or fatigue (personal), or workload and poor weather (situational)," whereas the second type includes factors "that physically inhibit the behavior, such as unavailability of a resource" (e.g., facilities, health educator, exercise leader; [14], p. 337). In the leisure literature, Jackson [29] argued that the term "constraint" has a wider meaning than the term "barrier", which fails to capture the whole range of explanations of constrained leisure behavior. According to Jackson and Scott [33], the term barrier refers mainly to external-to-theindividual constraints that intervene on the relationship between preference for an activity and actual participation. On the other hand, the term constraints is more general; it does not include only physical- and external-to-the-individual constraints (such as facility problems), but it includes also social (e.g., inability to find partners) and psychological constraints (e.g., perceived skills). These psychological 
constraints have a direct influence on an individual's preference for a specific activity [19].

On expanding the hierarchical model of leisure constraints, Jackson [29] proposed that the constraints that individuals perceive do not always lead to non-participation; they can also lead to modified participation. The negotiation of these constraints, with the development of appropriate strategies, determines, in a large degree, the final outcome (participation, non-participation, modified participation).

A variety of factors have been suggested by researchers to be related with this successful negotiation of leisure constraints, such as individuals' motivation, negotiation self-efficacy, and personal control [28, 32]. The personal control factor is a similar construct with the perceived behavioral control variable that has been included within the theory of planned behavior. Although the influence of motivation on negotiation and perceived constraints have been examined by some studies (e.g., $[10,18]$ ), there have been very limited attempts to investigate the relationship between constraints and variables related to individuals' attitudes. This relationship has been supported by a recent study [7] in which elements of the theory of planned behavior were shown to influence constraint dimensions.

The objective of the present study was to test the degree to which the elements of the theory of planned behavior act as mediators of the relationship between constraints and older individuals' intention to continuing participation in physical activity programs.

\section{Physical activity and aging}

Promoting physical activity among the elderly should be a high priority for policymakers today because international statistics show a general trend for the aging of the population in Western countries as a result of increased life expectancy and decline in birth rates [15, 40]. It is well documented today that physical activity participation is associated with a variety of physiological, psychological, and social benefits. Physical inactivity, on the other hand, is a public health concern because it has been associated with obesity and a greater risk for developing chronic illness and diseases [44]. Statistics from Eurobarometer [22] indicated that the majority $(60 \%)$ of individuals older than 65 years old in the European Union do not participate frequently in forms of moderate physical activities. Furthermore, only a small minority (15\%) spends more than $1 \mathrm{~h}$ per week in participating in physical activities. High figures of inactivity were reported for Spain and Italy, whereas lower figures were reported in The Netherlands [40]. With reference to Greece, the aging of the population follows similar patterns with Western societies due to increased life expectancy and reduced births. This trend is more pro- nounced in rural areas [26]. The statistics of Eurobarometer (http://www.ec.europa.eu) indicate that older Greek individuals' (more than 65 years old) participation rates in physical activities are on the average of the European Union members, with around $50 \%$ of them reporting no participation in any form of moderate physical activity in the contexts of work, home, and leisure. However, the percentage of physical inactivity during leisure time for older people in Greece is among the highest in the European Union. Less than $9 \%$ of the individuals reported regular participation in leisure-time physical activities/recreation.

\section{The theory of planned behavior}

The theory of planned behavior [1-3] is an extension of the theory of reasoned action [6, 23]. It proposes that an individual's intention to engage in a specific behavior (e.g., participate in a specific activity) is determined by (a) the individual's attitudes toward the behavior and (b) the influence of perceived social norms. Intention, in its turn, was proposed to act as a determinant of the actual behavior (e.g., actual participation levels). The attitudes are a function of the individual's attitudes concerning the consequences of engaging in this behavior, and a personal evaluation of these consequences, whereas the subjective norm component consists of the attitudes of the significant others (e.g., friends and family) concerning the individual's engagement in the specific behavior (e.g., participate in a specific activity). Ajzen [1, 2] extended the original theory of reasoned action by adding the component of perceived behavioral control that refers to an individual's perceptions about her/his capability of successfully engaging in the behavior [1]. The power of perceived behavioral control is related to the perceived resources (e.g., time, money, skills, and cooperation of other people) that an individual possesses and the existence or absence of perceived constraints [20]. Perceptions of internal (e.g., psychological) and external (lack of opportunities) constraints decrease perceptions of control over the behavior [4]. Perceived behavioral control was introduced in the theory to address the criticism in the assumption that human behavior is under the degree of volitional control $[1,2,5]$. Once again, volitional control is decreased as adequate resources (e.g., time, money, skills, and cooperation of other people), or perceived opportunities are decreased [35]. The literature on leisure constraints (see Jackson and Scott 1999) supports the argument that sport and leisure behaviors are not always under the degree of volitional control [43]. The theory of planned behavior has been applied to a variety of behaviors and has received widespread support in recent years. A variety of meta-analytic reviews have been conducted across different behaviors [11, 25, 27] and provided strong 
evidence on the predictive ability of the theory. In terms of the individual elements of the theory, the majority of the studies indicated that the perceived behavioral control variable is the most powerful one in predicting intentions and actual behavior [12, 24, 43].

\section{Perceived constraints}

Constraints have been defined as "the factors that are assumed by researchers and perceived by individuals to inhibit or prohibit participation and enjoyment in leisure" ([30], p.273). Crawford and Godbey [17] categorized constraints into intrapersonal, interpersonal, and structural constraints. Intrapersonal constraints are internal to an individual; they are mainly related to psychological states and attributes, such as lack of skills, perceived health problems, and perceptions about the availability of opportunities to participate. Interpersonal constraints are related to an individual's inability to find partners to participate with, whereas structural constraints are external to an individual and include factors related to lack of resources, facility, and financial problems. The hierarchical model of leisure constraints further proposed that intrapersonal constraints are the most powerful predictors of participation, which has been empirically supported by some studies $[8,10]$.

This proposition has been empirically verified by limited studies that examined constraints among older individuals. Intrapersonal constraints, such as ones that are psychologically related and related to lack of knowledge, were shown to significantly increase with advancing age $[8,21,30,38,41]$. On the other hand, external constraints, such as financially related constraints, were shown to decline with advancing age [30]. In terms of interpersonal constraints, studies have shown that older individuals reported lack of partner-related constraints more than the middle aged [30,38]. Finally, the lack of time-related constraints were shown to exhibit an inverted $U$ relationship with advancing age. Their importance increased from the youngest to the middle-aged groups and decreased among the older individuals [41].

As previously discussed, Jackson et al. [31] proposed that individuals develop negotiation strategies that help them overcome the effects of constraints. Although several studies $[16,36,37]$ have empirically verified and further explained these negotiation strategies, there have been limited efforts to investigate behavioral factors that might interact with constraints and determine participation [28]. There has been some evidence [9] that constraints have a negative impact on the intention to participate in physical activites and actual participation. Furthermore, Alexandris and Stodolska [7] argued that attitudinal variables included in the theory of planned behavior are related to the perception of constraints. Although their [7] study established the relationship between constraints and attitudes, it did not clarify if the elements of the theory of planned behavior mediate the constraintintention relationship. In the present study, it was hypothesized that the elements of the theory of planned behavior would mediate the relationship between constraints and intention for continuing participation. Because the relationships between the specific constraint dimensions (facilities, accessibility, psychological constraints, lack of partner) and the elements of the theory of planned behavior are not well established in the literature, we examined the mediating role of the elements of the theory of planned behavior on all the four constraint dimensions.

\section{Materials and methods}

\section{Participants and procedure}

This paper reports results of a larger study that investigated the behavioral aspects of physical activity among older individuals. The preliminary results of this study have been published in a previous paper [9]. Questionnaires were distributed to all individuals who participated in the physical activity programs provided at the Centers for Rehabilitation and Protection for the Older Individuals (KAPI) in Thessaloniki, Northern Greece. Before the data collection, permission was taken by the management committee of the center.

One hundred and forty five questionnaires were distributed, and $119(N=119)$ accepted to fill the questionnaires, achieving a response rate of $82 \%$. The mean age of the sample was 66.7 years $(\mathrm{SD}=5.21$, age range $=60$ to 86 years). The KAPI provide leisure and recreation opportunities for middle-aged and old individuals. They offer a variety of activities, such as sport programs, folklore dances, social gatherings, seminars, and leisure trips. The members of the facilities choose the activities in which they participate based on their personal interests. The physical activity programs (folklore dances, aerobic sessions, therapeutic recreation) run usually three times per week; this is the proposed frequency of participation for the members of KAPI. The questionnaires were distributed in the facilities by a team of graduate students under the supervision of the physical activity instructors. Participants filled the questionnaires in the facilities under the supervision of the research team.

Instruments

Four subscales were used to measure the elements of the theory of planned behavior. These scales have been widely used in the study of the theory of planned behavior with Greek populations [45]. 
Intention Three statements were used as follows: "I intend to participate in the physical activity programs provided by the center over the next month", "I will try to participate in the physical activities programs over the next month", and "I am determined to participate in the physical activity programs over the next month." A seven-point semantic differentiation scale ranging from 1 (very unlikely) to 7 (very likely) was used. The mean of the scale was taken as a composite score.

Attitudes toward the behavior It was measured using the seven-point bipolar adjective scales as suggested by [6]: "I think that my participation in physical activities is: useful vs. useless, hard vs. easy, important vs. not important, boring vs. interesting, unpleasant vs. pleasant, and good vs. bad." The mean of the scale was taken as a composite score.

Subjective norm Three statements were used as follows: "My physical activity participation is approved by (a) my husband/wife and children, (b) my relatives, and (c) my friends." A seven-point scale was used. The mean of the scale was taken as a composite score.

Perceived behavioral control It was measured with three items as follows: (a) "How much control do you have over you participation in the physical activity programs over the following month," on a seven-point scale that ranged from 1 (very little control) to 7 (complete control); (b) "If I want, I will be able to participate in the physical activity programs over the following month," on a seven-point scale ranging from 1 (never true) to 7 (always true); (c) "For me, to participate in the physical activity programs over the following month is easy," on a seven-point scale that ranged from 1 (strongly disagree) to 7 (strongly agree). The mean of the scale was taken as a composite score.

A principal component analysis of the scale measuring the theory of planned behavior variables indicated the existence of four distinct factors. The four factors explained $71.8 \%$ of the total variance. The loadings of the items included in the intention subscale ranged from 0.82 to 0.96 ; of the items included within the perceived behavioral control scale, range was from 0.56 to 0.87 ; of the items included within the attitudes scale, range was from 0.39 to 0.89 ; and of the items included within the subjective norm scale, range was from 0.43 to 0.84 . The Cronbach alpha values for the subscales were $\alpha=0.95$ for intention, $\alpha=0.76$ for attitudes, $\alpha=0.86$ for perceived behavioral control, and $\alpha=.70$ for subjective norm.

Constraints The scale developed by Alexandris and Carroll [8] was used to measure constraints. The respondents were asked to evaluate the importance of 15 statements as limiting factors for their current participation in the physical activity programs provided by the center. A seven-point Likert-type scale ranging from very important (7) to not important (1) was used. The mean of the scale was taken as a composite score. The results on the factorial validity of the scale (principal component analysis) in the same sample have been presented in a previous paper [9] and will not be presented in this paper. Four constraint factors emerged as follows: (a) facilities (four items), individual/psychological (five items), accessibility/financial (three items), and lack of partners (three items). The values of the alpha for all the subscales were reported to be very good, as they ranged from 0.89 to 0.91 .

\section{Results}

Descriptive and correlation analyses

The means and standard deviations of all the variables are shown in Table 1. In general, individuals expressed positive attitudes toward participating in physical activities and high levels of perceived control over their ability to participate in physical activities. The influence of significant others on their decision to participate in physical activities was shown to be relatively low. Furthermore, the older individuals expressed positive intention to participate in physical activities in the near future. Time and facilities were found to be the most important constraints, whereas accessibility, the less important one.

The correlation analysis indicated significant associations among the study's variables (Table 1). Intention was strongly correlated to perceived behavioral control, moderately correlated to attitudes, and weakly correlated to subjective norms. Furthermore, significant negative correlations were revealed between intention and the constraint dimensions. Attitudes were shown to be moderately correlated with subjective norms and perceived behavioral control. Significant correlations were also revealed between attitudes and all the constraint dimensions (Table 1). The perceived behavioral control was moderately correlated with subjective norms, whereas negative correlations were found with all the constraint dimensions. Finally, moderateto-strong positive correlations were revealed among the constraint components (Table 1).

Mediational analyses

According to Baron and Kenny [13], mediation is supported when the following four criteria are satisfied: (a) a significant correlation between the dependent (i.e., intention) and independent (i.e., constraints) variables, (b) a significant correlation between the independent variables 
Table 1 Means, standard deviations, and intercorrelations among the study's variables

\begin{tabular}{|c|c|c|c|c|c|c|c|c|c|c|c|}
\hline Variables & Mean & $\mathrm{SD}$ & Range & Variance & 1 & 2 & 3 & 4 & 5 & 6 & 7 \\
\hline 1. Intention & 5.91 & 1.87 & 6 & 2.68 & & & & & & & \\
\hline 2. Attitudes & 6.41 & 0.97 & 6 & 0.56 & $0.60 *$ & & & & & & \\
\hline 3. Subjective norm & 4.70 & 1.53 & 6 & 2.03 & $0.39 *$ & $0.41 *$ & & & & & \\
\hline 4. $\mathrm{PBC}$ & 5.20 & 1.78 & 6 & 2.62 & $0.69^{*}$ & $0.58^{*}$ & $0.51 *$ & & & & \\
\hline 5. Accessibility & 2.20 & 1.50 & 6 & 2.98 & $-0.37^{*}$ & $-0.40^{*}$ & -0.02 & $-0.34 *$ & & & \\
\hline 6. Facilities & 2.70 & 2.20 & 6 & 4.33 & $-0.28^{* *}$ & $-0.23 * *$ & -0.03 & $-0.22 * *$ & $0.69^{*}$ & & \\
\hline 7. Psychological & 2.91 & 1.50 & 6 & 2.76 & $-0.50 *$ & $-0.29 * *$ & -0.15 & $-0.53^{*}$ & $0.50 *$ & $0.56^{*}$ & \\
\hline 8. Partners & 2.45 & 1.90 & 6 & 3.00 & $-0.34^{*}$ & $-0.23 * *$ & -0.02 & $-0.23 * *$ & $0.62 *$ & $0.59 *$ & $0.57 *$ \\
\hline
\end{tabular}

$P B C$ Perceived behavioral control

$* p<0.001$

$* * p<0.05$

and the mediators (e.g., attitudes, perceived behavioral control, and subjective norm), (c) the mediators should have a significant unique effect on the dependent variable when they are included alongside the independent variable in a multivariate test of these relationships, and (d) the effect of the independent variable on the dependent should be significantly attenuated or nullified when the mediators are included as independent predictors of the dependent variable.

The correlation analysis revealed that intention was associated with all the components of the constraints, supporting the first criterion. In terms of the second criterion, it was satisfied for attitudes and perceived behavioral control. Both these components were shown to be significantly correlated with all the constraint dimensions. The subjective norm component was dropped from further mediation testing, as it was not found to be significantly correlated with any of the constraints' components (see Table 1).

To test the third criterion, a series of regression analyses were performed. The results indicated that attitudes satisfied the third criterion, as they contributed on the prediction of intention when they were entered alongside with accessibility $(b=0.51)$, psychological $(b=0.47)$, facilities $(b=0.54)$, and partners constraints $(b=0.52)$ in separate analyses. Subsequently, regression analyses were performed to test the effects of the above four constraint dimensions on intention. The results indicated that all of the four elements explained a unique variance on intention (Table 2). To test the fourth criterion, a set of regression analyses was performed, where attitudes were entered in the first step and constraints in the second step (accessibility in the first analysis, psychological in the second, facilities in the third, and partners in the fourth one). The results indicated that the inclusion of attitudes decreased the effect of accessibility ( $b=-0.16)$, psychological $(b=-0.37)$, facilities $(b=-0.15)$, and partners $(b=-0.16)$ on intention. These findings support the fourth criterion for mediation, indicating that attitudes mediate the influence of constraints on intention. An overview of the results of the regression analyses performed to test the mediating role of attitudes is shown in Table 2 and graphically presented in Fig. 1.

The same procedure was followed to test the mediation role of perceived behavioral control on accessibility, lack of partner, and psychological constraints. To test the third criterion for each case, regression analyses were performed. Perceived behavioral control satisfied the third criterion, as it was found to contribute on the prediction of intention when it was entered alongside with accessibility $(b=0.35)$, lack of partner $(b=0.30)$, psychological constraints $(b=0.31)$, and facilities $(b=0.26)$ in separate analyses. Subsequently, regression analyses were performed to test the effect of accessibility, lack of partner, and psychological constraints on intention. The results indicated that all the components explained a unique variance on intention (Table 2). To test the fourth criterion, a set of regression analyses was performed in which perceived behavioral control was entered in the first step and constraints in the second step (accessibility in the first analysis, lack of partner in the second analysis, and psychological and facility constraints in the third and fourth analyses, respectively). The results indicated that the inclusion of perceived behavioral control nullified the effects of partner $(b=-0.18)$, psychological $(b=-0.19)$, accessibility $(b=-0.13)$, and facilities $(b=-0.13)$ on intention. These findings support the fourth criterion for mediation, indicating that perceived behavioral control mediates the influence of constraints on intention. An overview of the results of the regression analyses performed to test the mediation role of perceived behavioral control is shown in Table 3 and graphically presented in Fig. 2.

\section{Discussion}

Previous studies in the area of leisure constraints reported weak negative relationships or, in some cases, non-relationships between perceived constraints and participation in sport and leisure activities [34, 42]. Jackson et al. [31] proposed 
Table 2 Regression analyses testing the mediating role of attitudes on the constraints' components-intention relationship

\begin{tabular}{|c|c|c|c|c|c|c|c|}
\hline Constraints & & $R^{2}$ & $F$ & $p$ & $b$ & $t$ & $P$ \\
\hline \multirow[t]{8}{*}{ Intention } & Attitudes $^{\mathrm{a}}$ & 0.36 & 20.20 & 0.001 & 0.51 & 4.96 & 0.001 \\
\hline & Attitudes ${ }^{\mathrm{b}}$ & 0.46 & 30.69 & 0.001 & 0.47 & 5.20 & 0.001 \\
\hline & Attitudes ${ }^{c}$ & 0.37 & 19.75 & 0.001 & 0.54 & 5.52 & 0.001 \\
\hline & Attitudes $^{\mathrm{d}}$ & 0.37 & 20.91 & 0.001 & 0.52 & 5.36 & 0.001 \\
\hline & Accessibility & 0.14 & 11.95 & 0.001 & -0.37 & -3.45 & 0.001 \\
\hline & Psychological & 0.26 & 25.23 & 0.001 & -0.50 & -6.04 & 0.001 \\
\hline & Facilities & 0.08 & 6.39 & 0.001 & -0.28 & -2.52 & 0.001 \\
\hline & Partners & 0.11 & 9.33 & 0.001 & -0.34 & -3.05 & 0.001 \\
\hline \multicolumn{8}{|l|}{ Intention } \\
\hline Step 1 & Attitudes & 0.33 & 37.18 & 0.001 & 0.51 & 4.96 & 0.001 \\
\hline Step 2 & Accessibility & 0.36 & 20.21 & 0.001 & -0.16 & -1.57 & NS \\
\hline \multicolumn{8}{|l|}{ Intention } \\
\hline Step 1 & Attitudes & 0.33 & 36.61 & 0.001 & 0.47 & 5.20 & 0.001 \\
\hline Step 2 & Psychological & 0.46 & 30.69 & 0.001 & -0.37 & -4.09 & 0.001 \\
\hline \multicolumn{8}{|l|}{ Intention } \\
\hline Step 1 & Attitudes & 0.33 & 36.05 & 0.001 & 0.54 & 5.52 & 0.001 \\
\hline Step 2 & Facilities & 0.35 & 19.75 & 0.001 & -0.15 & -1.62 & NS \\
\hline \multicolumn{8}{|l|}{ Intention } \\
\hline Step 1 & Attitudes & 0.33 & 34.70 & 0.001 & 0.52 & 5.36 & 0.001 \\
\hline Step 2 & Partners & 0.37 & 20.91 & 0.001 & -0.22 & -2.25 & 0.05 \\
\hline
\end{tabular}

${ }^{\text {a }}$ Analyses performed with accessibility serving as independent variable

${ }^{\mathrm{b}}$ Analyses performed with psychological constraints serving as independent variable

${ }^{c}$ Analyses performed with psychological constraints serving as independent variable with facilities serving as independent variable

${ }^{\mathrm{d}}$ Analyses performed with psychological constraints serving as independent variable with partner serving as independent variable

that these weak relationships might be due to the negotiation of leisure constraints. Although everybody faces and reports constraints, there are individuals who overcome them with the development of successful negotiation strategies. A variety of behavioral variables have been suggested in the literature to influence the success of these negotiation strategies, such as motivation and personality [28]. In the current study, we aimed to test if attitudes and perceived behavioral control interact with constraints and intervene within their relationship with intention to continuing physical activity participation. Based on the negotiation proposition [31], we aimed to test if the constraints that older individuals

Fig. 1 Attitudes as mediators of the constraint-intention relationship (numbers in brackets show betas after mediation was examined). a Accessibility served as independent variable, b psychological constraints served as independent variable, c lack of partner served as independent variable, and $\mathbf{d}$ facilities served as independent variable

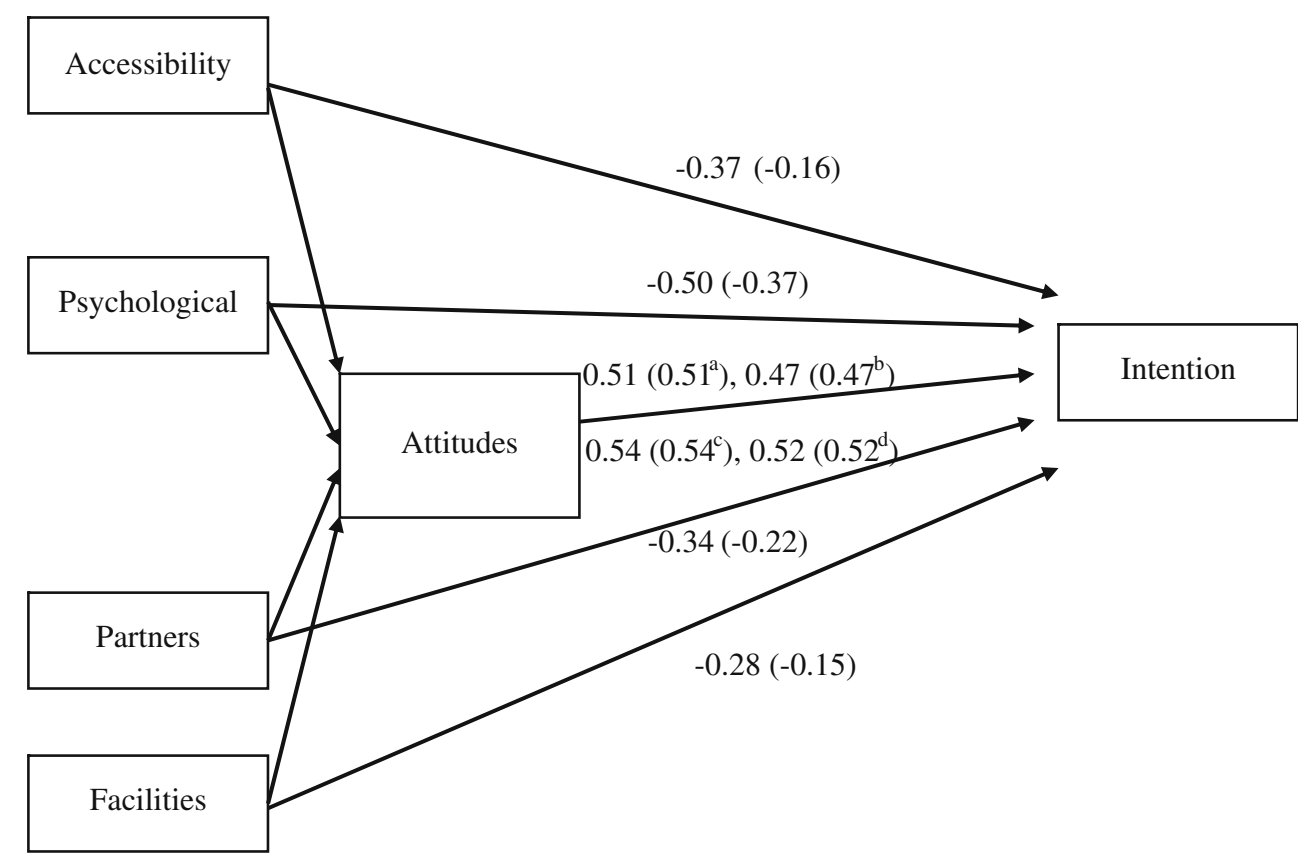


Table 3 Regression analyses testing the mediating role of perceived behavioral control on the constraints' components-intention relationship

\begin{tabular}{|c|c|c|c|c|c|c|c|}
\hline \multicolumn{2}{|l|}{ Constraints } & \multirow{2}{*}{$\frac{R^{2}}{0.35}$} & \multirow{2}{*}{$\frac{F}{18.71}$} & \multirow{2}{*}{$\frac{p}{0.001}$} & \multirow{2}{*}{$\frac{b}{b .43}$} & \multirow{2}{*}{$\frac{t}{4.62}$} & \multirow{2}{*}{$\frac{p}{0.001}$} \\
\hline Intention & $\mathrm{PBC}^{\mathrm{a}}$ & & & & & & \\
\hline & $\mathrm{PBC}^{\mathrm{b}}$ & 0.31 & 16.48 & 0.001 & 0.28 & 2.44 & 0.05 \\
\hline & $\mathrm{PBC}^{\mathrm{c}}$ & 0.30 & 15.15 & 0.001 & 0.44 & 4.31 & 0.001 \\
\hline & $\mathrm{PBC}^{\mathrm{d}}$ & 0.26 & 12.40 & 0.001 & 0.43 & 4.01 & 0.001 \\
\hline & Accessibility & 0.14 & 11.95 & 0.001 & -0.37 & -3.45 & 0.001 \\
\hline & Psychological & 0.26 & 25.23 & 0.001 & -0.50 & -6.04 & 0.001 \\
\hline & Facilities & 0.08 & 6.39 & 0.001 & -0.28 & -2.52 & 0.001 \\
\hline & Partners & 0.11 & 9.33 & 0.001 & -0.34 & -3.05 & 0.001 \\
\hline \multicolumn{8}{|l|}{ Intention } \\
\hline Step 1 & PBC & 0.48 & 68.29 & 0.001 & 0.64 & 7.24 & 0.001 \\
\hline Step 2 & Accessibility & 0.50 & 36.47 & 0.001 & -0.15 & -1.69 & NS \\
\hline \multicolumn{8}{|l|}{ Intention } \\
\hline Step 1 & $\mathrm{PBC}$ & 0.48 & 66.78 & 0.001 & 0.59 & 5.97 & 0.001 \\
\hline Step 2 & Psychological & 0.50 & 36.51 & 0.001 & -0.19 & -1.90 & $\mathrm{~ns}$ \\
\hline \multicolumn{8}{|l|}{ Intention } \\
\hline Step 1 & $\mathrm{PBC}$ & 0.49 & 67.20 & 0.001 & 0.65 & 7.64 & 0.001 \\
\hline Step 2 & Lack of partner & 0.52 & 37.74 & 0.001 & -0.18 & -2.17 & ns \\
\hline \multicolumn{8}{|l|}{ Intention } \\
\hline Step 1 & $\mathrm{PBC}$ & 0.47 & 65.60 & 0.001 & 0.66 & 7.60 & 0.001 \\
\hline Step 2 & Facilities & 0.49 & 34.63 & 0.001 & -0.13 & -1.54 & NS \\
\hline
\end{tabular}

$P B C$ Perceived behavioral control

${ }^{\text {a }}$ Analyses performed with accessibility serving as independent variable

${ }^{\mathrm{b}}$ Analyses performed with psychological constraints serving as independent variable

${ }^{\mathrm{c}}$ Analyses performed with partner serving as independent variable

${ }^{\mathrm{d}}$ Analyses performed with facilities serving as independent variable

report have a direct impact on intention, or an indirect one through their impact on perceived behavioral control and attitudes. We would expect that individuals who feel that they can control their behavior and/or will have positive attitudes toward physical activity would be more likely to overcome the influence of constraints.
The results of the study revealed some clear patterns. First of all, the element of subjective norms was not significantly associated with older individuals' intention to participate in physical activity programs. This finding supports previous studies [12, 24, 43]. It seems that older individuals are somewhat independent on their decisions
Fig. 2 Perceived behavioral control as mediator of the constraint-intention relationship (numbers in brackets show betas after mediation examined). a Accessibility served as independent variable, b psychological constraints served as independent variable, $\mathbf{c}$ lack of partner served as independent variable, and $\mathbf{d}$ facilities served as independent variable

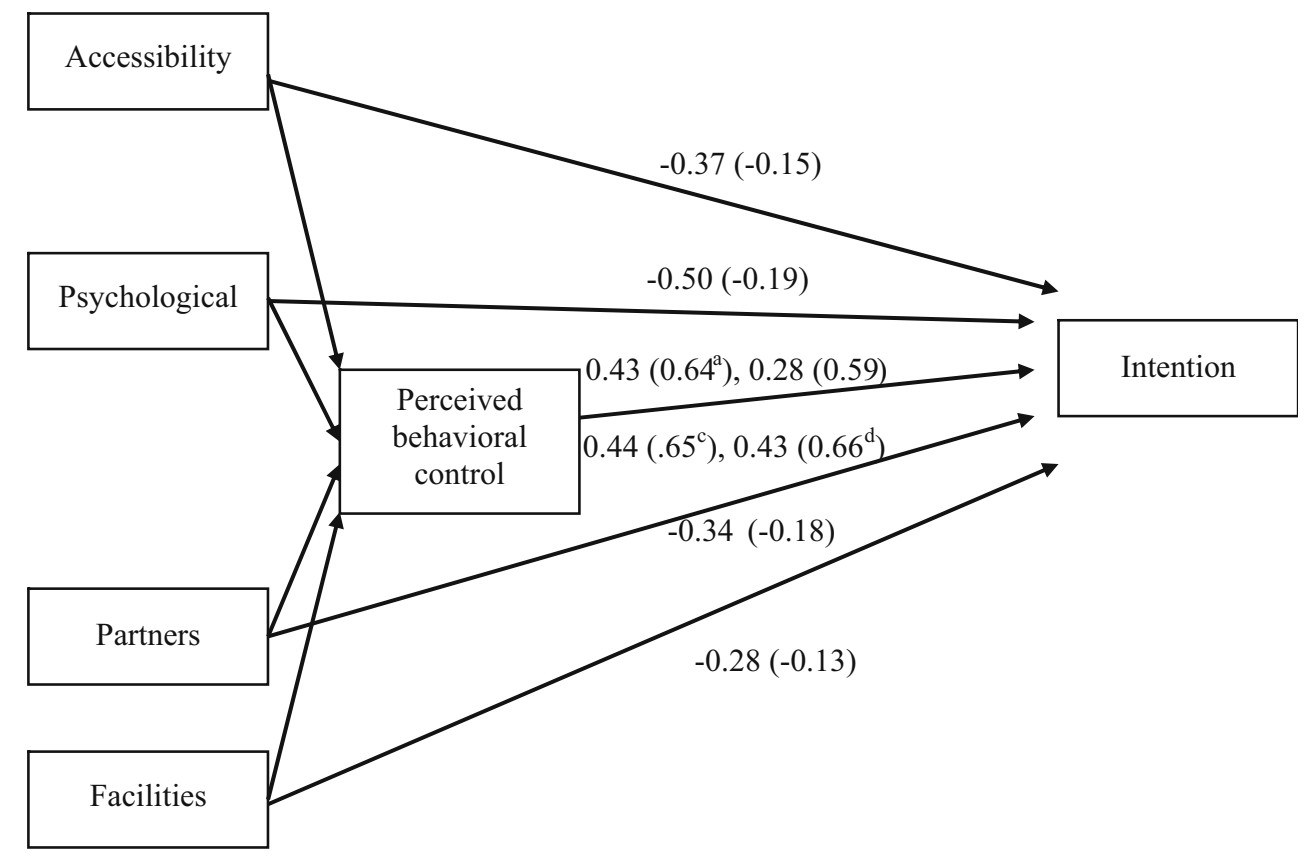


regarding physical activity participation. This might be due to the organized nature of the physical activity programs. All the individuals who participated in the research were members of KAPI and participated in the programs provided by KAPI. It is not clear if the results would have been the same if the question had been about physical activity participation in an unorganized setting. Previous studies have suggested that middle-aged and old individuals usually follow some stereotypes, do not always feel comfortable to participate in exercise and recreational programs, and are influenced by social contacts [39].

In terms of the relationship between constraint dimensions and the elements of the theory of planned behavior, the results revealed significant statistical associations among the variables. Both attitudes and perceived behavioral control were shown to be significantly correlated with all the constraint dimensions. As expected, all the correlations were negative. These results support the study conducted by Alexandris and Stodolska [7].

In terms of the role of perceived behavioral control and attitudes as mediators of the relationship between constraints and intention, some clear patterns were also revealed. First of all, both the variables were shown to be mediators, which suggests that constraints influence intention both directly and indirectly through their negative effects on attitudes and perceived behavioral control. Subsequently, individuals who face or perceive constraints are more likely to overcome them if they have developed positive attitudes toward physical activity and/or feel in control of their behavior. In terms of the strength of the mediation, perceived behavioral control was shown to be the strongest mediator. These findings support the negotiation proposition [30] and further extend it by suggesting two more behavioral variables (attitudes and perceived behavioral control) that could be included in future constraint models. As previously discussed, so far, only motivation had been shown to interact with constraints $[10,28]$.

In terms of the impact of the attitudes and perceived behavioral control on the specific constraint dimensions, the results indicated that attitudes fully mediated the influence of accessibility and facilities dimensions on intentions, and partially mediated the relationship between psychological and partners constraints and intention. This suggests that the psychological and lack-of-partners constraints have also a direct impact on individuals' intention to continuing physical activity participation. It should be noted that psychological constraints are perceived intrapersonally [18, 33], whereas lack-of-partners constraints are perceived interpersonally. Previous studies have reported intrapersonal constraints as the most powerful predictor of behavior [8, 33].

On the other hand, perceived behavioral control had a strong mediation effect on intrapersonal, interpersonal, and structural constraints. Whereas the mediation effect of perceived behavioral control on structural constraints was in a degree expected, considering previous studies in the area of leisure constraints [8], the mediation of perceived behavioral control on intrapersonal constraints was not expected to be so strong. Intrapersonal constraints have been found to be the most important blocking factors of behavior [10]; it seems that the alteration of perceptions of control might minimize the inhibiting role of intrapersonal constraints and enhance intention and, subsequently, participation behavior. These results support previous studies $[12,24,43]$ suggesting that perceived behavioral control is the most powerful predictor of intention and behavior within the theory of planned behavior. This proposes that practitioners should target perceived behavior control to reduce its effects. Consultation, education, psychological support, design, and delivery of appropriate programs are among the strategies that should be applied to reduce the influence of perceived behavioral control.

In conclusion, the study provided evidence that attitudes and perceived behavioral control interact with intention, and this interaction determines, in a large degree, older individuals' decision to continue taking part in physical activities. On the other hand, the subjective norm component was not shown to be significantly related with constraints. Furthermore, the results indicated that both attittudes and perceived behavioral control strongly mediated the relationship between constraints and intention, with the behavioral control component being the strongest mediator.

\section{Study limitations and future research}

It should be pointed out that the study was a cross-sectional one, which means that we were not able to trace individuals' future participation levels. The model tested was only based on individuals' intention to continue participating in physical activities. Future studies could adopt a longitudinal approach to test a model based on actual physical activity levels. This would give researchers the chance to further explore the role of constraints within individuals' decision making, considering also the "negotiation" construct proposed by Jackson [30]. Furthermore, the sample of the study was not large enough to ensure generalizations of the results. The model examined in the present study should be verified with larger samples in which detailed demographic information should be reported to test possible influences of socio-economic groups on the constraints-intention relationships.

In the present study, we tested the mediation effects of attitudes on the relationship between constraints and intention using regression models, following Baron and Kenny's [13] guidelines. Because we did not have an 
established theoretical framework for the relationships between constraints and the components of the theory of planned behavior, we did not apply structural modeling, which can be a suggested methodological approach for future studies that will aim to test the model proposed in the present study. It would also be interesting to test the model on different age groups and investigate possible changes on the perception of constraints and the influence of perceived behavioral control on intention with advancing age.

\section{References}

1. Ajzen I (1985) From intentions to actions: A theory of planned behavior. In: Kuhl J, Beckmann J (eds) Action control: from cognition to behavior. Springer, Berlin Heidelberg New York, pp 11-39

2. Ajzen I (1988) Attitudes, personality and behavior. Dorsey, Chicago

3. Ajzen I (1991) The theory of planned behavior. Org Behav Hum Decis Process 50:179-211

4. Ajzen I, Driver B (1991) Application of the theory of planned behavior to leisure choice. J Leis Res 24:207-224

5. Ajzen I, Madden T (1986) Prediction of goal-directed behavior: attitudes, intentions, and perceived behavioral control. J Exp Psychol 22:453-474

6. Ajzen I, Fishbein M (1980) Understanding attitudes and predicting social behavior. Prentice-Hall, Englewood Cliffs, NJ

7. Alexandris K, Stodolska M (2004) The influence of perceived constraints on the attitudes towards recreational sport participation. Leis Soc 27:197-217

8. Alexandris K, Carroll B (1997) An analysis of leisure constraints based on different recreational sport participation levels: results from a study in Greece. Leis Sci 19:1-15

9. Alexandris K, Barkoukis V, Tsorbatzoudis H, Grouios G (2003) A study of perceived constraints on a community-based physical activity program for the elderly in Greece. J Aging Phys Act 11:305-318

10. Alexandris K, Tsorbatzoudis H, Grouios G (2002) Perceived constraints on recreational participation: investigating their relationship with intrinsic motivation, extrinsic motivation and amotivation. J Leis Res 34:233-252

11. Armitage C, Conner M (2001) Efficacy of the theory of planned behavior: a meta-analytic review. Br J Soc Psychol 40:471-499

12. Armitage C, Conner M (1999) The theory of planned behavior: assessment of predictive validity and "perceived control". Br J Soc Psychol 38:35-54

13. Baron M, Kenny A (1986) The moderator-mediator variable distinction in social-psychological research: conceptual, strategic and statistical considerations. J Pers Soc Psychol 51:1173-1182

14. Brawley L, Martin K, Gyurcsik N (1998) Problems assessing perceived barriers to exercise: confusing obstacles with attributions and excuses. In: Duda J (ed) Advances in sport and exercise psychology measurement. Fitness Information Technology, Morgantown, pp 337-350

15. Chodzko-Zajko W (2000) Successful aging in the new millennium: the role of regular physical activity. Quest 52:333-343

16. Coble T, Selin S, Erickson B (2003) Hiking alone: understanding fear, negotiation strategies and leisure experiences. J Leis Res $35: 1-22$

17. Crawford D, Godbey G (1987) Reconceptualizing barriers to family leisure. Leis Sci 9:119-127
18. Carroll B, Alexandris K (1997) Perception of constraints and strength of motivation: their relation to recreational sport participation. J Leis Res 29:279-299

19. Crawford D, Jackson E, Godbey G (1991) A hierarchical model of leisure constraints. Leis Sci 13:309-320

20. Dawson K, Gyurcsik N, Culos-Reed N, Brawley L (2001) Perceived control: a construct that bridges theories of motivated behavior. In: Roberts G (ed) Advances in motivation in sport and exercise. Human Kinetics, Champaign, IL, pp 321-357

21. Dergance J, Calmbach W, Dhanda R, Miles T, Hazuda H, Mouton C (2003) Barriers to and benefits of leisure time physical activity in the elderly: differences across cultures. J Am Geriatr Soc $51: 863-868$

22. Eurobarometer (2002) Physical activity. European Commission. http://www.ec.europa.eu

23. Fishbein M, Ajzen I (1975) Belief, attitude, intention and behavior: an introduction to theory and research. AddisonWelsey, Reading, MA

24. Godin G (1993) The theories of reasoned action and planned behavior: overview of findings, emerging research problems and usefulness for exercise promotion. J Appl Sport Psychol 5:141-157

25. Hagger MS, Chatzisarantis N, Biddle S (2002) A meta-analytic review of the theories of reasoned action and planned behavior in physical activity: predictive validity and the contribution of additional variables. J Sport Exerc Psychol 24:3-32

26. Harahousou I (1999) Elderly people, leisure and physical recreation in Greece. World Leis Recreat 3:20-24

27. Hausenblas HA, Carron AV, Mack DE (1997) Application of the theories of reasoned action and planned behavior to exercise behavior: a meta analysis. J Sport Exerc Psychol 36-41

28. Hubbard J, Mannell R (2001) Testing competing models of the leisure constraint negotiation process in a corporate employee recreation setting. Leis Sci 23:145-163

29. Jackson EL (1991) Leisure constraints/constrained leisure: special issue introduction. J Leis Res 23:279-285

30. Jackson EL (1993) Recognizing patterns of leisure constraints: results from alternative analyses. J Leis Res 25:129-149

31. Jackson E, Crawford D, Godbey G (1993) Negotiation of leisure constraints. Leis Sci 15:1-12

32. Jackson E, Rucks V (1995) Negotiation of leisure constraints by junior-high and high-school students: an exploratory study. J Leis Res 23:301-313

33. Jackson E, Scott D (1999) Constraints to leisure. In: Jackson E, Burton $\mathrm{T}$ (eds) Leisure studies: prospects for the twenty first century. Venture, Pennsylvania, pp 299-321

34. Kay T, Jackson G (1991) Leisure despite constraint: the impact of leisure constraints on leisure participation. J Leis Res 23:301-313

35. Kimiecik J (1992) Predicting vigorous physical activity of corporate employees: comparing the theories of reasoned action and planned behavior. J Sport Exerc Psychol 14:192-206

36. Little D (2002) Women and adventure recreation: reconstructing leisure constraints and adventure experiences to negotiation continuing participation. J Leis Res 34:157-177

37. Livenwood J, Stodoloska M (2004) The effects of discrimination and constraints negotiation on leisure behavior of American Muslims in the Post-September 11 America. J Leis Res 36:183-208

38. McGuire F, Dottavio D, O'Leary L (1986) Constraints to participation in outdoor recreation across the life-span: a nation-wide study of limitors and prohibitors. Gerontologist 26:538-544

39. Satariano W, Haight T, Tager I (2002) Living arrangements and participation in leisure-time physical activities in an older population. J Aging Health 14:427-451 
40. Schuit A (2006) Physical activity, body composition and healthy ageing. Sci Sports 21:209-213

41. Searle M, Jackson E (1985) Recreation non-participation and barriers to participation: considerations for the management of recreation delivery systems. J Park Recreat Admi 3:23-35

42. Shaw S, Bonen A, McCabe J (1991) Do more constraints mean less leisure? Examining the relationship between constraints and participation. J Leis Res 23:286-300
43. Smith A, Biddle S (1999) Attitudes and exercise adherence: test of the theories of reasoned action and planned behavior. J Sport Sci 17:269-281

44. Spirduso W (1995). Physical dimensions of aging. Human Kinetics, Champaign, IL

45. Theodorakis Y (1994) Planned behavior, attitude strength, role identity, and the prediction of exercise behavior. Sport Psychol $8: 149-165$ 